OPEN ACCESS

Edited by:

Vaughan G. Macefield, Baker Heart and Diabetes Institute,

Australia

Reviewed by:

Winfried Neuhuber,

University of Erlangen Nuremberg,

Germany

Simon McMullan,

Macquarie University, Australia

*Correspondence:

Alexandria K. Driessen

ally.driessen@monash.edu

Specialty section:

This article was submitted to

Integrative Physiology,

a section of the journal

Frontiers in Physiology

Received: 30 May 2019

Accepted: 12 August 2019

Published: 28 August 2019

Citation:

Driessen AK (2019) Vagal Afferent

Processing by the Paratrigeminal

Nucleus.

Front. Physiol. 10:1110.

doi: 10.3389/fphys.2019.01110

\section{Vagal Afferent Processing by the Paratrigeminal Nucleus}

\author{
Alexandria K. Driessen* \\ School of Biomedical Science, Department of Anatomy and Neuroscience, University of Melbourne, Parkville, VIC, Australia
}

The paratrigeminal nucleus is an obscure region in the dorsal lateral medulla, which has been best characterized as a collection of interstitial cells located in the dorsal tip of the spinal trigeminal tract. The paratrigeminal nucleus receives afferent input from the vagus, trigeminal, spinal, and glossopharyngeal nerves, which contribute to its long-known roles in the baroreceptor reflex and nociceptive processing. More recently, studies have shown that this region is also involved in the processing of airway-derived sensory information. Notably, these studies highlight an underappreciated complexity in the neuronal content and circuit connectivity of the paratrigeminal nucleus. However, much remains to be understood about how paratrigeminal processing of vagal afferents is altered in disease. The aim of the present review is to provide an update of the current understanding of vagal afferent processing in the paratrigeminal nucleus and to explore how dysregulation at this site may contribute to vagal sensory neural dysfunction during disease.

Keywords: respiratory, nociception, jugular ganglia, paratrigeminal connectome, cough

\section{INTRODUCTION}

Vagal afferents innervating visceral tissues are well described to terminate in the medullary nucleus of the solitary tract (Cajal, 1909; Donoghue et al., 1982; Kubin et al., 1985; Mutoh et al., 2000; McGovern et al., 2012). However, it has also long been known that there are additional brainstem termination sites for vagal afferent fibers in the dorsal lateral medulla, including a region known as the paratrigeminal nucleus (Cajal, 1909; Altschuler et al., 1989; McGovern et al., 2012). Recent studies using viral circuit tracing of the airway sensory nervous system demonstrated that only a specific subset of vagal afferents project to the paratrigeminal nucleus (McGovern et al., 2015a) and since this observation there has been significant progress made toward understanding the role of the paratrigeminal nucleus in airway defense (Driessen et al., 2015, 2018). This brief review aims to bring together anatomical and functional investigations of the paratrigeminal nucleus to present a case for why this nucleus should be acknowledged as a second key processing site for vagal afferent inputs to the central nervous system.

\section{NEUROANATOMICAL STUDIES OF THE PARATRIGEMINAL NUCLEUS AND ITS CONNECTOME}

\section{Anatomically Defining the Paratrigeminal Nucleus}

The paratrigeminal nucleus is an obscure medullary region that was first characterized in the 1960s by Albert Rhoton. He defined this nucleus, in the monkey, as a collection of interstitial neurons located within the dorsal segment of the spinal trigeminal tract that is located in the lateral aspect of the medulla (Rhoton et al., 1966). Neurons in this region receive a 
diverse range of sensory inputs arising from trigeminal, glossopharyngeal, vagal sensory, and upper cervical dorsal root sensory ganglia (Ciriello et al., 1981; Panneton and Burton, 1981; Nomura and Mizuno, 1984; Altschuler et al., 1989; McGovern et al., 2012; Mahadi et al., 2019). Subsequent studies have identified comparable interstitial cells in the rat, guinea pig, cat, and human (Chan-Palay, 1978; Nasution and Shigenaga, 1987; Phelan and Falls, 1989; Pinto et al., 2006; Driessen et al., 2015; McGovern et al., 2015a). Phelan and Falls (1989) were the first to investigate the rostro-caudal extent of the paratrigeminal nucleus in the rat, showing that presumptive paratrigeminal neurons extend rostrally for approximately 1.5-2 $\mathrm{mm}$ from caudal to obex. Similarly, in the guinea pig, the paratrigeminal nucleus spreads $1.5 \mathrm{~mm}$ with the highest density of neurons located in the caudal $(-0.4 \mathrm{~mm}$ to obex $)$ and central (at the level of obex) aspects of this nucleus (Driessen et al., 2018).

Investigations of the cellular composition of the paratrigeminal nucleus have shown it to contain morphologically distinct subpopulations of neurons, as well as pronounced numbers of glia and astrocytes in its most superficial layers (Chan-Palay, 1978; Phelan and Falls, 1989; Saxon and Hopkins, 2006). The paratrigeminal nucleus is also enriched with a peptidergic neuropil, predominately expressing the neuropeptides calcitonin gene-related peptide and substance $\mathrm{P}$ that presumably represent the central terminal processes of the sensory neural inputs (Saxon and Hopkins, 2006; Caous et al., 2012; Driessen et al., 2015). Recent immunohistochemical characterization of the paratrigeminal nucleus in the guinea pig has demonstrated at least two distinct paratrigeminal neuron subtypes based on their immunoreactivity for either calbindin or the neurokinin 1 receptor (Driessen et al., 2018), analogous with the dorsal horn nociceptive system that contains phenotypically comparable neurons in receipt of nociceptive inputs (Li et al., 1999). However, this is unlikely a complete representation of the neuron subtypes that exist in the paratrigeminal nucleus and further neuronal heterogeneity may exist, like that in the dorsal horn (Hu et al., 2016; Li et al., 2016; Jurcakova et al., 2018). It seems reasonable to speculate that this under-appreciated complexity of the paratrigeminal nucleus likely confers functional significance with respect to the integration and processing capabilities of this nucleus.

\section{Vagal Afferent Terminations in the Paratrigeminal Nucleus}

Vagal afferents have their cell bodies located in either the jugular (superior) or nodose (inferior) vagal ganglia (Canning et al., 2004; Undem et al., 2004; McGovern et al., 2012). These two ganglia are derived from different embryological origins (D’Autréaux et al., 2011; Nomaksteinsky et al., 2013) and this confers significant differences in the physiology, pharmacology, and neuroanatomy of the neurons originating in each (Kwong et al., 2008; Chang et al., 2015; McGovern et al., 2015a,b; Nonomura et al., 2017; Kupari et al., 2019). Studies of airway projecting vagal sensory neurons in the mouse and guinea pig indicate that the visceral placodal nodose-derived neurons are characteristically non-peptidergic consisting of myelinated $\mathrm{A} \delta$ - or $\mathrm{A} \beta$ - fibers and unmyelinated C-fibers (Riccio et al., 1996; Undem et al., 2004; Mazzone and Undem, 2016) that can be selectively activated by serotonin 5 -HT3 receptor agonists and adenosine $5^{\prime}$-triphosphate (ATP) as they uniquely express the purinergic receptors P2X2 and P2X3 (Kwong et al., 2008; Potenzieri et al., 2012). On the other hand, airway somatic neural crest-derived jugular neurons are classically characterized as non-peptidergic $\mathrm{A} \delta$-fibers or peptidergic $\mathrm{C}$-fibers unresponsive to both 5-HT and ATP due to lack of expression of 5HT3 and P2X2 receptors (Riccio et al., 1996; Canning et al., 2004; Undem et al., 2004; Potenzieri et al., 2012). Recent single-cell RNA sequencing of unidentified nodose and jugular afferent neurons in the mouse reveal comparable phenotypic differences, with jugular neurons demonstrating more similarities to neurons of the dorsal root ganglia, which is underpinned by their developmental origin (Kupari et al., 2019).

In the guinea pig, viral tract tracing using an adeno-associated virus encoding green fluorescent protein (AAV2/8-eGFP) microinjected into the vagal sensory ganglia revealed that vagal afferents predictably project to the nucleus of the solitary tract, and additionally to the caudal and central regions of the paratrigeminal nucleus, which are the medullary levels that align with the highest density of postsynaptic neurons (Driessen et al., 2018). Similarly, tracing in the rat of vagally innervated viscera, the pharynx and larynx show bilateral afferent projections to both the nucleus of the solitary tract and the paratrigeminal nucleus (Saxon and Hopkins, 2006). Furthermore, direct electrical stimulation of the vagus nerve (Rutherfurd et al., 1992) or larynx (Wang et al., 2015) results in neuronal activation of paratrigeminal neurons. These data raise the question of whether paratrigeminal projecting vagal afferents represent a distinct population of neurons from the nodose or jugular vagal ganglia. McGovern et al. (2015b) addressed this by performing tracing studies of the afferents innervating different levels of the respiratory tree. In doing so, they showed that the lungs are predominately innervated by afferents from the nodose ganglia, while the upper airways (larynx, trachea, and mainstem bronchi) are innervated by the neurons derived from the jugular ganglia (McGovern et al., 2015b). Subsequent dual retrograde neural tracing studies in rats and guinea pigs confirmed the existence of differential vagal inputs to brainstem processing sites demonstrating that nodose vagal afferents project exclusively to the nucleus of the solitary tract, while the jugular vagal ganglia afferents project almost entirely to the paratrigeminal nucleus (Figure 1A; Driessen et al., 2015; McGovern et al., 2015a). These studies suggest that two parallel vagal sensory circuits exist, broadly classified as either a nodose-nucleus of the solitary tract processing pathway or jugular-paratrigeminal processing pathway.

\section{Paratrigeminal Nucleus Output Connectivity}

Neuronal tracing studies in both rat and guinea pig have shown output projections from paratrigeminal neurons to bulbar nuclei integral to autonomic and nociceptive processing, 

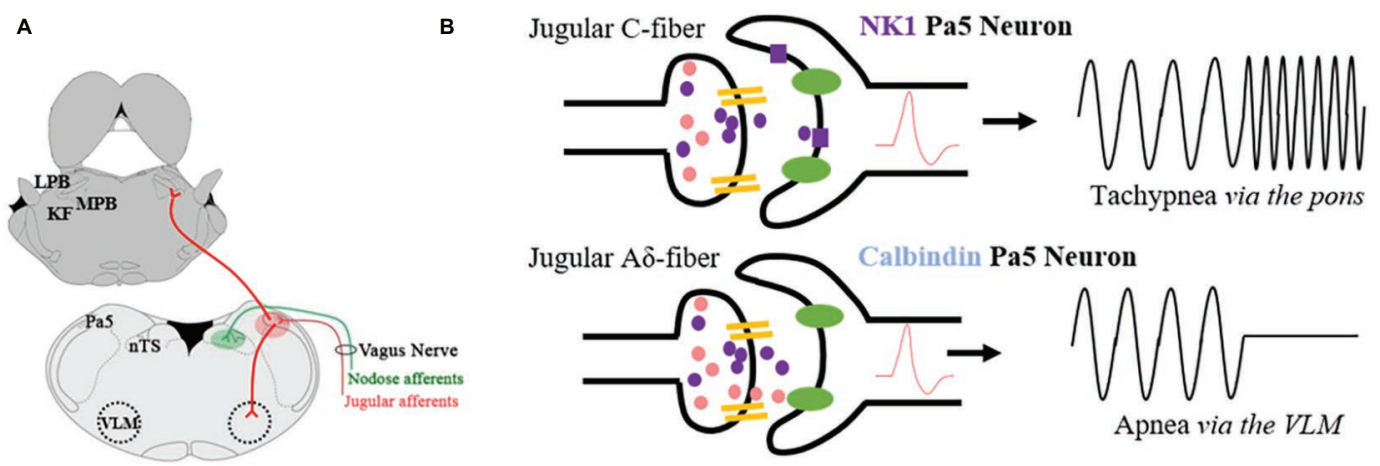

- Glutamate Glutamate receptor $\rightleftharpoons$ TRPVI

- Neuropeptide (e.g. substance P) Neurokinin I receptor

FIGURE 1 | Schematic representation of the anatomical and functional specificity of the paratrigeminal nucleus (Pa5). (A) Illustration of jugular vagal afferents (red) specifically terminating in the Pa5, located in the dorsal-lateral medulla. Conversely, the nodose vagal afferents (green) exclusively project to the nucleus of the solitary tract (nTS). Jugular vagal afferent inputs are first synaptically integrated with Pa5 neurons, which differentially project to additional bulbar nuclei involved in cardiorespiratory control. Depicted are a subset of Pa5 neurons projecting to the ventrolateral medulla (VLM), and a separate population ascending to the pontine nuclei that collectively include the Kölliker Fuse (KF) nucleus and lateral (LPB) and medial (MPB) parabrachial nuclei. (B) Stylized diagram depicting a hypothesis for how the neuroanatomical organization of the Pa5 underpins functional specificity at this site based on studies of laryngeal-evoked reflexes in guinea pigs (Driessen et al., 2018). Non-peptidergic jugular A-fibers expressing the transient receptor potential vanilloid 1 (TRPV1) appear to mediate the abrupt cessation in breathing (apnea) observed when the larynx is electrically or chemically stimulated. Synaptically, this response is dependent on fast ionotropic glutamatergic neurotransmission in the Pa5, and it is hypothesized that calbindin expressing Pa5 neurons projecting to cardiorespiratory cells of the ventrolateral medulla are principally involved. Peptidergic (e.g.,

substance P containing fibers) inputs to the Pa5 are likely responsible for increased respiratory drive (i.e., tachypnea). Physiological or pathophysiological conditions that allow for neuropeptide release will activate NK1 receptor expressing Pa5 neurons, which possibly ascend the neuraxis and terminate diffusely in the pons. This pathway may contribute to respiratory and autonomic processing via these pontine circuits or excite bulbar-circuits involved in sensory discrimination.

including the nucleus of the solitary tract, spinal trigeminal nuclei, rostral ventrolateral medulla, nucleus ambiguus, reticular nuclei, parabrachial nuclei, Kölliker-Fuse nucleus, and principal sensory trigeminal nucleus (Feil and Herbert, 1995; Saxon and Hopkins, 1998; Caous et al., 2001; de Sousa Buck et al., 2001; Pinto et al., 2006; McGovern et al., 2015b; Driessen et al., 2018). While no monosynaptic projections were observed above the level of the pons in the guinea pig (Driessen et al., 2018), ascending projections directly to the somatosensory thalamus (ventroposterior medial thalamus) have been observed in rats (Saxon and Hopkins, 1998; Pinto et al., 2006; McGovern et al., 2015a). Interestingly, dual cholera-toxin retrograde tracing studies have shown different projection patterns of subpopulations of paratrigeminal neurons (Saxon and Hopkins, 1998; Pinto et al., 2006; Driessen et al., 2018). For example, Pinto et al. (2006) showed topography of pontine projections could be mapped across the rostrocaudal extent of the paratrigeminal nucleus, indicative of selective pontomedullary connectivity. Additionally, in the rat, separate paratrigeminal neurons project to the parabrachial nuclei compared to the ventroposterior medial thalamus (Saxon and Hopkins, 1998), while in the guinea pig there are distinct neurons that project to the parabrachial nuclei compared to the ventrolateral medulla (Figure 1A; Driessen et al., 2018). Given that at least two populations of phenotypically different paratrigeminal neurons exist (expressing neurokinin 1 receptors or calbindin; Driessen et al., 2018), it will be important to investigate whether these populations preserve a level of connectivity specificity.

\section{THE PHYSIOLOGICAL ROLE OF THE PARATRIGEMINAL NUCLEUS IN VAGAL AFFERENT REGULATION OF CARDIORESPIRATORY CONTROL}

Vagal afferent inputs from aortic baroreceptors to the brainstem play an essential role in the regulation of blood pressure via circuits involving the ventrolateral medulla (Bonham and Jeske, 1989; Ruggiero et al., 1996; Choong et al., 2013; Koganezawa and Paton, 2014; Tallapragada et al., 2016; Ghali, 2017). Although many baroreceptive afferents terminate centrally in the nucleus of the solitary tract, neurons in the paratrigeminal nucleus also demonstrate baroreceptor-related activity (Caous et al., 2001; de Sousa Buck et al., 2001). In the rat, up to $72 \%$ of paratrigeminal neurons are barosensitive and of these almost all show rhythmic activity with the cardiac cycle (Balan Júnior et al., 2004; Sousa and Lindsey, 2009). Importantly, baroreceptor reflex evoked changes in cardiovascular activity is modulated by altering synaptic processing in the paratrigeminal nucleus. Thus, microinjection of bradykinin into the paratrigeminal nucleus results in increased arterial pressure, while lesioning this nucleus increases resting arterial pressure and heart rate and impairs baroreceptor reflex sensitivity (Lindsey et al., 1997; Sousa and Lindsey, 2009). Although not proven, these effects are presumably mediated by paratrigeminal neuronal connectivity with the ventrolateral medulla. However, some entrainment of barosensitive neural activity in the paratrigeminal nucleus and the nucleus of the solitary tract suggests functional interconnectivity between these vagal sensory processing sites (Balan Júnior et al., 2004). 
Vagal afferents are essential for maintaining appropriate airway patency and adequate respiration. In anesthetized animals, nodose vagal stimulation results in apnea via slowly adapting lung stretch receptors (Knowlton and Larrabee, 1946; Backman et al., 1984; Kubin et al., 1985; Widdicombe, 2001; Nonomura et al., 2017), tachypnea via rapidly adapting mechanoreceptors or C-fibers (Chou et al., 2008), or cough via the activation of the specialized mechanically sensitive nodose A $\delta$-fibers (the cough receptor) in the upper airways (Canning et al., 2004, 2006; Mazzone et al., 2009). A full description of nodoseevoked responses is beyond the scope of this review.

Conversely, only a few studies have specifically investigated the effects of jugular vagal stimulation on respiration. In guinea pigs, jugular vagal afferents evoke an apnea in anesthetized animals when stimulated and mediate coughing in response to inhaled noxious chemicals in conscious animals (Chou et al., 2008, 2018; Driessen et al., 2015, 2018). The apneic response, readily induced from the guinea pig larynx (Driessen et al., 2015, 2018), is perhaps consistent with the reported role of the paratrigeminal nucleus in the diving reflex whereby stimulation of trigeminal afferents in the nose promotes breath holding (Panneton et al., 2000; McCulloch et al., 2018). Indeed, the jugular vagal innervation to the larynx is particularly dense an either electrical stimulation or topically applied capsaicin evokes a profound withdrawal of respiratory drive. This reflex response to laryngeal stimulation is abolished by generalized inhibition of the paratrigeminal nucleus, but not the nucleus of the solitary tract, using microinjections of the GABA receptor antagonist muscimol (Driessen et al., 2015). Furthermore, laryngeal-evoked reductions in breathing are predominately dependent upon glutamatergic neurotransmission in the paratrigeminal nucleus, while neuropeptides appear to play a neuromodulatory role (Figure 1B; Driessen et al., 2018). Consistent with this, apneas can also be induced by activation of neurons in the paratrigeminal nucleus by direct microinjection of glutamate (Driessen et al., 2018). Together, these functional data support the role of jugular vagal afferents in suppressing respiratory drive.

Intriguingly, when the central terminals of afferents in the paratrigeminal nucleus are activated using microinjection of capsaicin, a slowly developing but long-lasting tachypnea is observed, distinctly opposite to the abrupt apneas described above. This tachypneic response is unaffected by glutamate antagonism but abolished in the presence of substance P receptor antagonists (Driessen et al., 2018). Whether this effect is mediated by vagal afferent nerve fibers is not known. However, these data suggest that at least two distinct neural circuits arise from the paratrigeminal nucleus and display opposing effects on respiration.

The potential role of the paratrigeminal nucleus in cough has not been investigated but is predicted based on the known role of jugular vagal afferents in evoking coughing (Hewitt et al., 2016; Chou et al., 2018). In conscious guinea pigs, inhaled chemical stimuli that activate both nodose and jugular nociceptors (e.g., capsaicin, bradykinin, citric acid) reliably evoke cough, whereas selective stimuli of nodose nociceptors (ATP, adenosine and 5HT) do not evoke coughing (Chou et al., 2018). Furthermore, nicotine selective for jugular afferents ( $\mathrm{Gu}$ et al., 2008; Tao et al., 2019) readily induces cough (Forsberg et al., 1988; Lee et al., 2007), as does Arnold's reflex involving stimulation of the auricular branch of the vagus nerve (Ryan et al., 2014; Dicpinigaitis et al., 2019) whose fibers are derived from the jugular vagal ganglia (DuBois and Folley, 1937). A hypersensitive Arnold's reflex has now been shown to be a biomarker that defines chronic cough (Dicpinigaitis et al., 2019) and in turn could be a promising therapeutic target given that transcutaneous vagal stimulation at this site has been shown to be important for a variety of cardiovascular conditions (Murrary et al., 2016). How jugular afferent inputs are integrated in the paratrigeminal nucleus to coordinate cough and other changes to respiration has not been studied.

\section{THE PARATRIGEMINAL NUCLEUS AND CONSCIOUS PERCEPTION OF VAGAL AFFERENTS}

The ascending circuits from the paratrigeminal nucleus largely involve somatosensory processing regions of the thalamus and cortex (Ralston, 2005; McGovern et al., 2015a) and this may implicate the jugular-paratrigeminal pathway in the conscious perception of jugular vagal inputs to the brain. Indeed, the paratrigeminal nucleus has been shown to be involved in processing pain (Ma et al., 2005; Koepp et al., 2006). With respect to the vagal system, this has been best studied for airway jugular nociceptors. In guinea pigs and rats, jugular vagal afferents are most concentrated in the large proximal airways (McGovern et al., 2015b; Driessen et al., 2018), which are the structures most commonly associated with perceivable sensations (Ando et al., 2014; Hilton et al., 2015). In this regard, it is interesting that previous studies have shown that jugular vagal afferents are important for the induction of coughing evoked by noxious chemical stimuli in conscious but not anesthetized animals (Mazzone et al., 2005), where conscious perception is presumably absent. In humans, stimulation of upper airway structures innervated by jugular afferents evokes a sensory experience known as the urge-to-cough (Mazzone et al., 2011) that while in healthy individuals is relieved by coughing; in disease, these irritations persist contributing to chronic cough and increased morbidity associated with respiratory disease (Chung, 2011; Morice, 2013). A hypothesis is that the urge-to-cough and associated cough is dependent upon jugular C-fibers synapsing with neurokinin 1 receptor expressing paratrigeminal neurons. In the medullary dorsal horn, neurokinin 1 receptor expressing neurons are excitatory and project to higher order circuits that are important for discriminative and emotive processing associated with orofacial pain (Cameron et al., 2015; Li et al., 2017). Furthermore, with respect to cough, neurokinin 1 receptor antagonists have shown to be antitussive in both animal and human studies (Amadesi et al., 2001; Chapman et al., 2004; El-Hashim et al., 2004; Grobman and Reinero, 2016). Therefore, future studies aiming to define the organization of the jugular-neurokinin 1 receptor paratrigeminal circuitry in cough will improve our understanding of the airway sensory nervous system and in turn generate new and improved treatment options for sufferers of respiratory disease. 


\section{CONCLUSION: SIGNIFICANCE AND FUTURE DIRECTIONS}

The paratrigeminal nucleus has an undeniable role in the processing of vagal afferent inputs. It has roles in both autonomic and nociceptive processing acting akin to the nucleus of the solitary tract and dorsal horn respectively in a context specific manner. However, the extent of this involvement has largely remained unstudied, perhaps reflecting the technical difficulties associated with studying jugular vagal afferents and this small region of the brainstem. Consequently, many questions remain about the mechanistic processing of different sensory modalities and their integration in the paratrigeminal nucleus. To this end, it will be interesting to determine the relative contributions of jugular A- and C-fiber sensory neural inputs into different paratrigeminal circuits (Figure 1B) and to define the physiological circumstance under which neuropeptides are released. Indeed recent advancements in molecular phenotyping of vagal sensory neurons (Kupari et al., 2019), the development of new viral vector systems and advances in imaging technologies may lead to novel approaches for investigating this neuronal circuitry.

However, it is also important to recognize that our current understanding of this topic is derived predominately from studies in healthy animals. Therefore, we likely have an under-appreciation of the importance of this nucleus in aberrant vagal afferent processing, which is well known to accompany the symptoms of disease. As such, it will be intriguing to investigate the potential plasticity in afferent processing that occurs in the paratrigeminal nucleus in a disease context, as this may provide new insights into the manifestation of heightened sensitivity and exaggerated

\section{REFERENCES}

Altschuler, S. M., Bao, X. M., Bieger, D., Hopkins, D. A., and Miselis, R. R. (1989). Viscerotopic representation of the upper alimentary tract in the rat: sensory ganglia and nuclei of the solitary and spinal trigeminal tracts. J. Comp. Neurol. 283, 248-268. doi: 10.1002/cne.902830207

Amadesi, S., Moreau, J., Tognetto, M., Springer, J., Trevisani, M., Naline, E., et al. (2001). NK1 receptor stimulation causes contraction and inositol phopsphate increase in medium size human isolated bronchi. Am. J. Respir. Crit. Care Med. 163, 1206-1211. doi: 10.1164/ajrccm.163.5.2002079

Ando, A., Farrell, M. J., and Mazzone, S. B. (2014). Cough-related neural processing in the brain: a roadmap for cough dysfunction? Neurosci. Biobehav. Rev. 47, 457-468. doi: 10.1016/j.neubiorev.2014.09.018

Backman, S. B., Anders, C., Ballantyne, D., Röhrig, N., Camerer, H., Mifflin, S., et al. (1984). Evidence for a monosynaptic connection between slowly adapting pulmonary stretch receptor afferents and inspiratory beta neurones. Pflugers Arch. 402, 129-136. doi: 10.1007/BF00583324

Balan Júnior, A., Caous, C. A., Yu, Y. G., and Lindsey, C. J. (2004). Barosensitive neurons in the rat tractus solitarius and paratrigeminal nucleus: a new model for medullary, cardiovascular reflex regulation. J. Physiol. Pharmacol. 82, 474-484. doi: 10.1139/y04-054

Bonham, A. C., and Jeske, I. (1989). Cardiorespiratory effects of DL-Homocysteic acid in caudal centrolateral medulla. Am. J. Phys. 256, H688-H696. doi: 10.1152/ajpheart.1989.256.3.H688

Cajal, S. R. (1909). Histologie du système nerveaux de l'homme et des vertébrés. (Paris: Maloine).

Cameron, D., Polgár, E., Gutierrez-Mecinas, M., Gomez-Lima, M., Watanabe, M., and Todd, A. J. (2015). The organisation of spinoparabrachial neurons in the mouse. Pain 156, 2061-2071. doi: 10.1097/j.pain.0000000000000270 reflexes that are characteristic of many visceral conditions. The trigeminal system (including the paratrigeminal area) has been implicated as a key region in chronic pain arising from the face (Imbe and Ren, 1999; Yamazaki et al., 2008). Under these conditions, the neurons of the trigeminal sensory nuclei have increased excitability that is likely underpinned by increased neuropeptide production and altered neuron-glial cross talk (Devesa et al., 2014; Romero-Reyes et al., 2015; Yang et al., 2016; Chen et al., 2017). In addition, changes in higher order circuitry have been described (Hayes et al., 2017). Similar sensory plasticity in the paratrigeminal nucleus may occur in visceral diseases and this could be especially relevant in conditions of vagal hypersensitivities, in which altered neurochemistry of jugular-paratrigeminal afferent processing may be an underlying feature of the associated sensory disturbances. This should be a matter of interest because sensory hypersensitivities accompanying visceral disease have proven difficult to treat and the paratrigeminal nucleus may represent a novel alternate target for therapeutic intervention.

\section{AUTHOR CONTRIBUTIONS}

The author confirms being the sole contributor of this work and has approved it for publication.

\section{ACKNOWLEDGMENTS}

The author would like to acknowledge and thank the support of the Picchi Brothers Foundation.

Canning, B. J., Mazzone, S. B., Meeker, S. N., Mori, N., Reynolds, S. M., and Undem, B. J. (2004). Identification of the tracheal and laryngeal afferent neurones mediating cough in anaesthetized Guinea-pigs. J. Physiol. 557, 543-558. doi: 10.1113/jphysiol.2003.057885

Canning, B. J., Mori, N., and Mazzone, S. B. (2006). Vagal afferent nerves regulating the cough reflex. Respir. Physiol. Neurobiol. 152, 223-242. doi: 10.1016/j.resp.2006.03.001

Caous, C. A., de Sousa Buck, H., and Lindsey, C. J. (2001). Neuronal connections of the paratrigeminal nucleus: a topographic analysis of neurons projecting to bulbar, pontine and thalamic nuclei related to cardiovascular, respiratory and sensory functions. Auton. Neurosci. 94, 14-24. doi: 10.1016/S1566-0702 (01)00338-1

Caous, C. A., Smith, R. L., Haapalainen, E. F., and Lindsey, C. J. (2012) Ultrstructural transneuronal degeneration study of axonal elements within the paratrigeminal nucleus in sinoaortic deafferented rats. Einstein 10, 145-150. doi: 10.1590/S1679-45082012000200006

Chang, R. B., Strochlic, D. E., Williams, E. K., Umans, B. D., and Liberles, S. D. (2015). Vagal sensory neuron subtypes that differentially control breathing. Cell 161, 622-633. doi: 10.1016/j.cell.2015.03.022

Chan-Palay, V. (1978). The paratrigeminal nucleus. II. Identification and interrelations of catecholamine axons, indoleamine axons and substance $\mathrm{P}$ immunoreactive cells in the neuropil. J. Neurocytol. 7, 419-412. doi: 10.1007/ BF01173989

Chapman, R. W., House, A., Liu, F., Celly, C., Mei, H., and Hey, J. A. (2004) Antitussive activity of the tachykinin NK1 receptor antagonist, CP-99994, in dogs. Eur. J. Pharmacol. 485, 329-332. doi: 10.1016/j.ejphar.2003.11.048

Chen, S. P., Qin, T., Seidel, J. L., Zheng, Y., Eikermann, M., Ferrari, M. D., et al. (2017). Inhibition of the P2X7-PANX1 complex suppresses spreading depolarisation and neuroinflammation. Brain 140, 1643-1656. doi: 10.1093/ brain/awx085 
Choong, Y. T., Menuet, C., Jancovski, N., and Allen, A. M. (2013). Baroreceptor reflex control of heart rate in angiotensin type $1 \mathrm{~A}$ receptor knockout mice. Phys. Rep. 1:e00171. doi: 10.1002/phy2.171

Chou, Y. L., Mori, N., and Canning, B. J. (2018). Opposing effects of bronchopulmonary C-fiber subtypes on cough in Guinea-pigs. Am. J. Phys. Regul. Integr. Comp. Phys. 314, R489-R498. doi: 10.1152/ajpregu.00313.2017

Chou, Y. L., Scarupa, M. D., Mori, N., and Canning, B. J. (2008). Differential effects of airway afferent nerve subtypes on cough and respiration in anesthetized Guinea pigs. Am. J. Phys. Regul. Integr. Comp. Phys. 295, R1572-R1584. doi: 10.1152/ajpregu.90382.2008

Chung, K. F. (2011). Chronic 'cough hypersensitivty syndrome': a more precise label for chronic cough. Pulm. Pharmacol. Ther. 24, 267-271. doi: 10.1016/j. pupt.2011.01.012

Ciriello, J., Hrycyshyn, A. W., and Calaresu, F. R. (1981). Glossopharyngeal and vagal afferent projections to the brain stem of the cat: a horseradish peroxidase study. J. Auton. Nerv. Syst. 4, 63-79.

D’Autréaux, F., Coppola, E., Hirsch, M. R., Birchmeier, C., and Brunet, J. F. (2011). Homeoprotein Phox $2 \mathrm{~b}$ commands a somatic-to-visceral switch in cranial sensory pathways. Proc. Natl. Acad. Sci. USA 108, 20018-20023. doi: $10.1073 /$ pnas. 1110416108

de Sousa Buck, H., Caous, C. A., and Lindsey, C. J. (2001). Projections of the paratrigeminal nucleus to the ambiguus, rostroventrolateral and lateral reticular nuclei, and the solitary tract. Auton. Neurosci. 87, 187-200. doi: 10.1016/ S1566-0702(00)00259-9

Devesa, I., Ferrándiz-Huertas, C., Mathivanan, S., Wolf, C., Luján, R., Changeux, J. P., et al. (2014). aCGRP is essential for algesic exocytotic mobilisation of TRPV1 channels in peptidergic nociceptors. Proc. Natl. Acad. Sci. U. S. A. 111, 18345-18350. doi: 10.1073/pnas.1420252111

Dicpinigaitis, P. V., Enilari, O., and Cleven, K. L. (2019). Prevelance of Arnold nerve reflex in subjects with and without chronic cough: relevance to cough hypersensitivity syndrome. Pulm. Pharmacol. Ther. 54, 22-24. doi: 10.1016/j. pupt.2018.11.003

Donoghue, S., Garcia, M., Jordan, D., and Spyer, K. M. (1982). The brain-stem projections of pulmonary stretch afferent neurons in cats and rabbits. J. Physiol. 322, 353-363. doi: 10.1113/jphysiol.1982.sp014041

Driessen, A. K., Farrell, M. J., Dutschmann, M., Stanic, D., McGovern, A. E., and Mazzone, S. B. (2018). Reflex regulation of breathing by the paratrigeminal nucleus via multiple bulbar circuits. Brain Struct. Funct. 223, 4005-4022. doi: 10.1007/s00429-018-1732-z

Driessen, A. K., Farrell, M. J., Mazzone, S. B., and McGovern, A. E. (2015). The role of the paratrigeminal nucleus in vagal afferent evoked respiratory reflexes: a neuroanatomical and functional study in Guinea pigs. Front. Physiol. 6:378. doi: 10.3389/fphys.2015.00378

DuBois, F. S., and Folley, J. O. (1937). Quantitiative studies of the vagus nerve in the cat. II. The ratio of jugular to nodose fibers. J. Comp. Neurol. 67, 69-87.

El-Hashim, A. Z., Wyss, D., and Lewis, C. (2004). Effect of a novel NK1 receptor selective antagonist (NKP608) on citric acid induced cough and airway obstruction. Pulm. Pharmacol. Ther. 17, 11-18. doi: 10.1016/j. pupt.2003.08.002

Feil, K., and Herbert, H. (1995). Topographic organization of spinal and trigeminal somatosensory pathways to the rat parabrachial and Kolliker-fuse nuclei. J. Comp. Neurol. 353, 506-528. doi: 10.1002/cne.903530404

Forsberg, K., Karlsson, J. A., Theodorsson, E., Lundberg, J. M., and Persson, C. G. (1988). Cough and bronchoconstriction mediatted by capsaicin-sensitive sensory neurons in the Guinea pig. Pulm. Pharmacol. 1, 33-39. doi: 10.1016/0952-0600(88)90008-7

Ghali, M. G. Z. (2017). The brainstem network controlling blood pressure: an important role for pressor sites in the caudal medulla and cervical spinal cord. J. Hypertens. 35, 1938-1947. doi: 10.1097/HJH.0000000000001427

Grobman, M., and Reinero, C. (2016). Investigation of neurokinin-1 receptor antagonism as a novel treatment for chronic bronchitis in dogs. J. Vet. Intern. Med. 30, 847-852. doi: 10.1111/jvim.13935

Gu, Q., Ni, D., and Lee, L. Y. (2008). Expression of neuronal nicotinic acetylcholine receptors in rat vagal pulmonary sensory neurons. Respir. Physiol. Neurobiol. 161, 87-91. doi: 10.1016/j.resp.2007.11.006

Hayes, D. J., Chen, D. Q., Zhong, J., Lin, A., Behan, B., Walker, M., et al. (2017). Affective circuitry alterations in patients with trigeminal neuralgia. Front. Neuroanat. 11:73. doi: 10.3389/fnana.2017.00073
Hewitt, M. M., Adams, G. Jr., Mazzone, S. B., Mori, N., Yu, L., Canning, B. J., et al. (2016). Pharmacology of bradykinin-evoked coughing in guinea pigs. J. Pharmacol. Exp. Ther. 357, 620-628.

Hilton, E., Marsden, P., Thurston, A., Kennedy, S., Decalmer, S., and Smith, J. A. (2015). Clinical features of the urge-to-cough in patients with chronic cough. Respir. Med. 109, 701-707. doi: 10.1016/j.rmed.2015.03.011

Hu, G., Huang, K., Hu, Y., Du, G., Xue, Z., Zhu, X., et al. (2016). Single-cell RNA-seq reveals distinct injury responses in different types of DRG sensory neurons. Sci. Rep. 6:31851. doi: 10.1038/srep31851

Imbe, H., and Ren, K. (1999). Orofacial deep and cutaneous tissue inflammation differentially upregulates preprodynorphin mRNA in the trigeminal and paratrigeminal nuclei of the rat. Brain Res. Mol. Brain Res. 67, 87-97. doi: 10.1016/S0169-328X(99)00040-6

Jurcakova, D., Ru, F., Kollarik, M., Sun, H., Krajewski, J., and Undem, B. J. (2018). Voltage-gated sodium channels regulating action potential generation in itch-, nociceptive-, and low threshold mechanosensitive cutaneous C-fibres. Mol. Pharmacol. 94, 1047-1056. doi: 10.1124/mol.118.112839

Knowlton, G. C., and Larrabee, M. G. (1946). A unitary analysis of pulmonary volume receptors. Am. J. Phys. 147, 100-114.

Koepp, J., Lindsey, C. J., Motta, E. M., and Rae, G. A. (2006). Role of the paratrigeminal nucleus in nocifensive responses of rats to chemical, thermal and mechanical stimuli applied to the hind paw. Pain 122, 235-244. doi: 10.1016/j.pain.2006.01.038

Koganezawa, T., and Paton, J. F. (2014). Intrinsic chemosensitivity of rostral ventrolateral medullary sympathetic premotor neurons in the in situ arterially perfused preparation of rats. Exp. Physiol. 99, 1453-1466. doi: 10.1113/ expphysiol.2014.080069

Kubin, L., Alheid, G. F., Zuperku, E. J., and McCrimmon, D. R. (1985). Central pathways of pulmonary and lower airway vagal afferents. J. Appl. Physiol. 101, 618-627.

Kupari, J., Häring, M., Agirre, E., Castelo-Branco, G., and Ernfors, P. (2019). An atlas of vagal sensory neurons and their molecular specialization. Cell Rep. 27, 2508-2523. doi: 10.1016/j.celrep.2019.04.096

Kwong, K., Kollarik, M., Nassenstein, C., Ru, F., and Undem, B. J. (2008). P2X2 receptors differentiate placodal vs. neural crest C-fiber phenotypes innervating Guinea pig lungs and esophagus. Am. J. Phys. Lung Cell. Mol. Phys. 295, L858-L865. doi: 10.1152/ajplung.90360.2008

Lee, L. Y., Burki, N. K., Gerhardstein, D. C., Gu, Q., Kou, Y. R., and Xu, J. (2007). Airway irritation and cough evoked by inhlaed cigarette smoke: role of neuronal nicotinic acetylcholine receptors. Pulm. Pharmacol. Ther 20, 355-364. doi: 10.1016/j.pupt.2006.10.007

Li, C. L., Li, K. C., Wu, D., Chen, Y., Luo, H., Zhao, J. R., et al. (2016). Somatosensory neuron types identified by high-coverage single-cell RNAsequencing and functional heterogenity. Cell Res. 26:967. doi: 10.1038/ cr.2016.90

Li, J. L., Li, Y. Q., Li, J. S., Kaneko, T., and Mizuno, N. (1999). Calciumbinding protein-immunoreactive projection neurons in the caudal subnucleus of the spinal trigeminal nucleus of the rat. Neurosci. Res. 35, 225-240. doi: 10.1016/S0168-0102(99)00086-3

Li, X., Ge, S. N., Li, Y., and Wang, H. T. (2017). Neurokinin-1 receptorimmunopositive neurons in the medullary dorsal horn provide collateral axons to both the thalamus and parabrachial nucleus in rats. Neurochem. Res. 42, 375-388. doi: 10.1007/s11064-016-2080-0

Lindsey, C. J., Buck, H. S., Fior-Chadi, D. R., and Lapa, R. C. (1997). Pressor effect mediated by bradykinin in the paratrigeminal nucleus of the rat. J. Physiol. 502, 119-129. doi: 10.1111/j.1469-7793.1997.119bl.x

Mahadi, K. M., Lall, V. K., Deuchars, S. A., and Deuchars, J. (2019). Cardiovascular autonomic effects of transcutanoues auricular nerve stimulation via the tragus in the rat involve spinal cervical sensory afferent pathways. Brain Stimul. 12, 1151-1158. doi: 10.1016/j.brs.2019.05.002

Ma, W. L., Zhang, W. B., Feng, G., and Cai, Y. L. (2005). Calbindin D28kcontaining neurons in the paratrigeminal nucleus receive convergent nociceptive information and project to nucleus of the solitary tract in rat. Brain Res. 1038, 132-140. doi: 10.1016/j.brainres.2005.01.021

Mazzone, S. B., Cole, L. J., Ando, A., Egan, G. F., and Farrell, M. J. (2011). Investigation of the neural control of cough and cough suppression in humans using functional brain imaging. J. Neurosci. 31, 2948-2958. doi: 10.1523/JNEUROSCI.4597-10.2011 
Mazzone, S. B., Mori, N., and Canning, B. J. (2005). Synergistic interactions between airway afferent nerve subtypes regulating the cough reflex in Guineapigs. J. Physiol. 569, 559-573. doi: 10.1113/jphysiol.2005.093153

Mazzone, S. B., Reynolds, S. M., Mori, N., Kollarik, M., Farmer, D. G., Myers, A. C., et al. (2009). Selective expression of a sodium pump isozyme by cough receptors and evidence for its essential role in regulating cough. J. Neurosci. 29, 13662-13671. doi: 10.1523/JNEUROSCI.4354-08.2009

Mazzone, S. B., and Undem, B. J. (2016). Vagal afferent innervation of the airways in health and disease. Physiol. Rev. 96, 975-1024. doi: 10.1152/ physrev.00039.2015

McCulloch, P. F., Lahrman, K. A., DelPrete, B., and DiNovo, K. M. (2018). Innervation of the nose and nasal region of the rat: implication for initiating the mammalian diving response. Front. Neuroanat. 12:85. doi: 10.3389/fnana.2018.00085

McGovern, A. E., Davis-Poynter, N., Farrell, M. J., and Mazzone, S. B. (2012). Transneuronal tracing of airways-related sensory circuitry using herpes simplex virus 1, strain H129. Neuroscience 207, 148-166. doi: 10.1016/j. neuroscience.2012.01.029

McGovern, A. E., Driessen, A. K., Simmons, D. G., Powell, J., Davis-Poynter, N., Farrell, M. J., et al. (2015a). Distinct brainstem and forebrain circuits receiving tracheal sensory neuron inputs revealed using a novel conditional anterograde transsynaptic viral tracing system. J. Neurosci. 35, 7041-7055. doi: 10.1523/JNEUROSCI.5128-14.2015

McGovern, A. E., Davis-Poynter, N., Yang, S. K., Simmons, D. G., Farrell, M. J., and Mazzone, S. B. (2015b). Evidence for multiple sensory circuits in the brain arising from the respiratory system: an anterograde viral tract tracing study in rodents. Brain Struct. Funct. 220, 3683-3699. doi: 10.1007/s00429-014-0883-9

Morice, A. H. (2013). Chronic cough hypersensitivity syndrome. Cough 9, 14-18. doi: 10.1186/1745-9974-9-14

Murrary, A. R., Atkinson, L., Mahadi, M., Deuchars, S., and Deuchars, J. (2016). The strange case of the ear and the heart: the auricular vagus nerve and its influence on cardiac control. Auton. Neurosci. 199, 48-53. doi: 10.1016/j. autneu.2016.06.004

Mutoh, T., Bonham, A. C., and Joad, J. P. (2000). Substance P in the nucleus of the solitary tract augments bronchopulmonary C fibre reflex output. Am. J. Phys. Regul. Integr. Comp. Phys. 279, R1215-R1223. doi: 10.1152/ ajpregu.2000.279.4.R1215

Nasution, I. D., and Shigenaga, Y. (1987). Ascending and descending internuclear projections within the trigeminal sensory nuclear complex. Brain Res. 425, 234-247. doi: 10.1016/0006-8993(87)90506-3

Nomaksteinsky, M., Kassabov, S., Chettouh, Z., Stoeklé, H. C., Bonnaud, L., Fortin, G., et al. (2013). Ancient origin of somatic and visceral neurons. BMC Biol. 11:53. doi: 10.1186/1741-7007-11-53

Nomura, S., and Mizuno, N. (1984). Central distribution of primary afferent fibers in the Arnold's nerve (the auricular branch of the vagus nerve): a transganglionic HRP study in the cat. Brain Res. 292, 199-205. doi: 10.1016/0006-8993(84)90756-X

Nonomura, K., Woo, S. H., Chang, R. B., Gillich, A., Qiu, Z., Francisco, A. G., et al. (2017). Piezo2 sense airway stretch and mediates lung inflation-induced apnoea. Nature 541, 176-181. doi: 10.1038/nature20793

Panneton, W. M., and Burton, H. (1981). Corneal and periocular representation within the trigeminal sensory complex in the cat studied with transganglionic transport of horseradish peroxidase. J. Comp. Neurol. 199, 327-344. doi: 10.1002/cne.901990303

Panneton, W. M., McCulloch, P. F., and Sun, W. (2000). Trigemino-autonomic connections in the muskrat: the neural substrate for the diving response. Brain Res. 874, 48-65. doi: 10.1016/S0006-8993(00)02549-X

Phelan, K. D., and Falls, W. M. (1989). The interstitial system of the spinal trigeminal tract in the rat: anatomical evidence for morphological and functional heterogeneity. Somatosens. Mot. Res. 6, 367-399.

Pinto, M. L., de Cássia Machado, R., Schoorlemmer, G. H., Colombari, E., and de Cássia Ribeiro da Silva Lapa, R. (2006). Topographic organization of the projections from the interstitial system of the spinal trigeminal tract to the parabrachial nucleus in the rat. Brain Res. 1113, 137-145. doi: 10.1016/j. brainres.2006.07.028

Potenzieri, C., Meeker, S., and Undem, B. J. (2012). Activation of mosue bronchopulmonary C-fibres by serotonin and allergen-ovalbumin challenge. J. Physiol. 590, 5449-5559. doi: 10.1113/jphysiol.2012.237115
Ralston, H. J. 3rd (2005). Pain and the primate thalamus. Prog. Brain Res. 149, 1-10. doi: 10.1016/S0079-6123(05)49001-9

Rhoton, A. L. Jr., O'leary, J. L., and Ferguson, J. P. (1966). The trigeminal, facial, vagal and glossopharyngeal nerves in the monkey. Afferent connections. Arch. Neurol. 14, 530-540.

Riccio, M. M., Kummer, W., Biglari, B., Myers, A. C., and Undem, B. J. (1996). Interganglionic segregation of distinct vagal afferent fibre phenotypes in Guinea-pig airways. J. Physiol. 496, 521-530. doi: 10.1113/jphysiol.1996.sp021703

Romero-Reyes, M., Pardi, V., and Akerman, S. (2015). A potent and selective calcitonin gene-related peptide (CGRP) receptor anatongist, MK-8825, inhibits responses to nociceptive trigeminal activation: a role of CGRP in orofacial pain. Exp. Neurol. 271, 95-103. doi: 10.1016/j.expneurol.2015.05.005

Ruggiero, D. A., Tong, S., Anwar, M., Gootman, N., and Gootman, P. M. (1996). Hypotension-induced expression of the $\mathrm{c}$-fos gene in the medulla oblongata of piglets. Brain Res. 706, 199-209. doi: 10.1016/0006-8993(95)01173-0

Rutherfurd, S. D., Widdop, R. E., Sannajust, F., Louis, W. J., and Gundlach, A. L. (1992). Expression of c-fos and NGFI-A messenger RNA in the medulla oblongata of the anaesthetized rat following stimulation of vagal and cardiovascualr afferents. Brain Res. Mol. Brain Res. 13, 301-312. doi: 10.1016/0169-328X(92)90213-U

Ryan, N. M., Gibson, P. G., and Birring, S. S. (2014). Arnold's nerve cough reflex: evidence for chronic cough as a sensory vagal neuropathy. J. Thorac. Dis. 6, S748-S752. doi: 10.3978/j.issn.2072-1439.2014.04.22

Saxon, D. W., and Hopkins, D. A. (1998). Efferent and collateral organization of paratrigeminal nucleus projections: an anterograde and retrograde fluorescent tracer study in the rat. J. Comp. Neurol. 402, 93-110. doi: 10.1002/(SICI )1096-9861(19981207)402:1<93::AID-CNE7>3.0.CO;2-A

Saxon, D. W., and Hopkins, D. A. (2006). Ultrastructure and synaptology of the paratrigeminal nucleus in the rat: primary pharyngeal and laryngeal afferent projections. Synapse 59, 220-234. doi: 10.1002/syn.20233

Sousa, L. O., and Lindsey, C. J. (2009). Discharge rate profiles of paratrigeminal nucleus neurons throughout a pressor event in non-anaesthetised rats. Auton. Neurosci. 147, 20-26. doi: 10.1016/j.autneu.2008.12.012

Tallapragada, V. J., Hildreth, C. M., Burke, P. G., Raley, D. A., Hassan, S. F., McMullan, S., et al. (2016). Tonically active cAMP-dependent signalling in the ventrolateral medulla regulates sympathetic and cardiac vagal outflows. J. Pharmacol. Exp. Ther. 356, 424-433. doi: 10.1124/jpet.115.227488

Tao, M., Liu, Q., Miyazaki, Y., and Canning, B. J. (2019). Nicotinic receptor dependent regulation of cough and other airway defensive reflexes. Pulm. Pharmacol. Ther. 58:101810. doi: 10.1016/j.pupt.2019.101810

Undem, B. J., Chuaychoo, B., Lee, M. G., Weinreich, D., Myers, A. C., and Kollarik, M. (2004). Subtypes of vagal afferent C-fibres in Guinea-pig lungs. J. Physiol. 556, 905-917. doi: 10.1113/jphysiol.2003.060079

Wang, X., Guo, R., and Zhao, W. (2015). Distribution of Fos-like immunoreactivity catecholaminergic and serotinergic neurons activated by the laryngeal chemoreflex in the medulla oblongata of rats. PLoS One 10:e130822. doi: 10.1371/journal.pone.0130822

Widdicombe, J. (2001). Airway receptors. Respir. Physiol. 125, 3-15. doi: 10.1016/ S0034-5687(00)00201-2

Yamazaki, Y., Ren, K., Shimada, M., and Iwata, K. (2008). Modulation of paratrigeminal nociceptive neurons following temporomandibular joint inflammation in rats. Exp. Neurol. 214, 209-218. doi: 10.1016/j.expneurol.2008.08.005

Yang, Y. J., Hu, L., Xia, Y. P., Jiang, C. Y., Miao, C., Yang, C. Q., et al. (2016). Resveratrol suppresses glial activation and alleviates trigeminal neuralgia via activation of AMPK. J. Neuroinflammation 13, 84-95. doi: 10.1186/ s12974-016-0550-6

Conflict of Interest Statement: The author declares that the research was conducted in the absence of any commercial or financial relationships that could be construed as a potential conflict of interest.

Copyright (c) 2019 Driessen. This is an open-access article distributed under the terms of the Creative Commons Attribution License (CC BY). The use, distribution or reproduction in other forums is permitted, provided the original author(s) and the copyright owner(s) are credited and that the original publication in this journal is cited, in accordance with accepted academic practice. No use, distribution or reproduction is permitted which does not comply with these terms. 